\title{
PLASMA CHROMOGEN AND THE ENDOGENOUS CREATININE CLEARANCE
}

\author{
BY \\ M. H. ROSCOE \\ From the Department of Medicine, Manchester University
}

(RECEIVED FOR PUBLICATION OCTOBER 4, 1957)

\begin{abstract}
One of the troubles of using the endogenous creatinine clearance to measure the filtration rate is that plasma and serum contain chromogens, other than creatinine, which give a colour with the Jaffé reaction. The creatinine can, however, be isolated by adsorption on Fuller's earth (Gaebler and Keltch, 1928) and subsequently eluted with the alkaline picrate used for colour production (Borsook, 1935). This method has been used by a number of workers and its reliability established. Thus Hare and Hare (1949) found with radioactive carbon that recovery is complete, and Ralston (1955) with chromatography that no extraneous chromogen remains after treatment. But there is very little evidence as to the amounts of non-creatinine chromogen in the plasma or as to how neglect of its presence influences the creatinine clearance, and it is these points which will be considered here.
\end{abstract}

\section{Method}

Chromogens in Serum.-The extraneous chromogen is taken as the difference between total chromogen in untreated serum filtrates and true creatinine in the same filtrates treated with Fuller's earth. The total and extraneous chromogen are expressed as the amount of creatinine giving the same colour.

Reagents.-The following were used :

Standard creatinine solution, $0.5 \mathrm{~g}$. in 1 litre $\frac{\mathrm{N}}{10} \mathrm{HCl}$ and dilutions with water to suitable strengths.

$5 \%(w / v)$ sodium tungstate.

$0.33 \mathrm{~N}_{3} \mathrm{H}_{2} \mathrm{SO}_{4}$.

Fuller's earth (B.D.H.), 10 g. in $100 \mathrm{ml}$. of water.

Oxalic acid, saturated solution $(9.5 \mathrm{~g}$. in $100 \mathrm{ml}$. of water).

$0.75 \mathrm{~N} . \mathrm{NaOH}(3 \%)$.

Picric acid, saturated solution.

Protein Precipitation.-Take two $2.5 \mathrm{ml}$. samples of serum in centrifuge tubes; to one (X) add $2.5 \mathrm{ml}$. of water and to the other (S) $2.5 \mathrm{ml}$. of $20 \mathrm{mg}$./1. creatinine solution and mix. To each add $2.5 \mathrm{ml}$. sodium tungstate and $2.5 \mathrm{ml} . \mathrm{H}_{2} \mathrm{SO}_{4}$. Mix and stand 10 minutes. Centrifuge and filter. When estimations are made both with and without adsorption double quantities must be used.

Total Chromogens.-To $5 \mathrm{ml}$. each of $\mathrm{X}, \mathrm{S}$, and water, add $3 \mathrm{ml}$. of a fresh mixture of equal parts of picric acid and $\mathrm{NaOH}$. The colour of $\mathrm{X}$ is read against the $\mathrm{H}_{2} \mathrm{O}$ blank and that of $\mathrm{S}$ against $\mathrm{X}$, readings being made after 25 to 30 minutes at room temperature with a Spekker absorptiometer and bluegreen filters, No. 603.

Creatinine.-To $5 \mathrm{ml}$. each of $\mathrm{X}, \mathrm{S}$, and water, in conical centrifuge tubes, add $1 \mathrm{ml}$. of Fuller's earth suspension and $0.5 \mathrm{ml}$. of oxalic acid. Stopper with plastic bungs and shake intermittently for 10 minutes. Remove bungs and wash them and the sides of the tube with a few drops of water. Centrifuge at 3,000 r.p.m. for 20 minutes. Decant the supernatant fluid and drain in reverse.

To the packed deposit add $8 \mathrm{ml}$. alkaline picrate solution made from 3 parts each of picric acid and $\mathrm{NaOH}$ and 10 parts of water. Stir, stopper, and shake intermittently for 10 minutes. Centrifuge for 10 minutes. The supernatant fluid is then poured off into the absorptiometer cuvettes and the colour of $X$ read against the water blank, that of $S$ against $X$. Readings are made at room temperature, the colour being fully developed at 30 minutes and remaining stable for several hours. Plastic bungs are better than rubber ones, since alkaline picrate removes a coloured compound from the latter if they are at all worn.

The concentrations of either total chromogen or creatinine are then given by the calculation:

$$
\left(\frac{\text { Reading of } \mathrm{X}}{\text { Reading of } \mathrm{S}} \times 20\right) \text { mg./1. creatinine. }
$$

When the creatinine content of the serum is two to three times higher than normal, dilution is necessary. This is carried out after protein precipitation. The amount of standard creatinine added to the serum must then be increased so as to give a final concentration of $5 \mathrm{mg}$. $/ 1$.

In addition to the internal standard, which is all that is needed for routine estimations, when total chromogen and true creatinine are being compared, standards in water of 2.5 to $10 \mathrm{mg}$./1. are used, both with and without treatment with Fuller's earth. The value of the serum is then read from the standard 
curve in water and corrected for the colour depression which occurs in serum.

Thus if

$$
\begin{aligned}
& \text { Reading of serum }=0.15=15.6 \mathrm{mg} . / \mathrm{l} . \\
& \text { Reading of serum }+ \\
& 5 \mathrm{mg} . / 1 \text {. standard }=0.345 \\
& \text { Expected reading of } \\
& 15.6+5.0 \mathrm{mg} . / 1 . \quad=0.363 \\
& \text { Corrected serum concentration }
\end{aligned}
$$

$$
=15.6 \times \frac{0.363}{0.345}=16.4 \mathrm{mg} . / 1 \text {. }
$$

Creatinine Excretion Rates and Clearances.-The excretion rates are obtained from the means of three to 16 samples of urine. Creatinine is estimated in the urine without adsorption with Fuller's earth, since it has been shown that little if any extraneous chromogen is present (Hare and Hare, 1949 ; Owen, Iggo, Scandrett, and Stewart, 1954).

The mean minute excretion of creatinine divided by the total chromogen or creatinine in $1 \mathrm{ml}$. of urine gives the uncorrected creatinine clearance.

\section{Results}

The colours of alkaline creatinine picrate and alkaline picrate are influenced by the medium in which the creatinine is present and the temperature. In seram, creatinine gives less colour than in water (Roscoe, 1953) so that a standard in serum should be used, but the colour depression is les when the serum filtrates are treated with Fuller's earth than when they are untreated. Thus the colour given by creatinine added to 20 serun samples is $5.5 \%$ (S.D. 3.5) less than the expected without adsorption, only $1.6 \%$ (S.D. 2.3) less with adsorption. With adsorption there will, therefores only be a small error if standards in water are used instead of the internal one, but these must be treated with Fuller's earth, because after treatment there is about $10 \%$ reduction in colour in all cons centrations.

The colours of both alkaline picrate and alkaline creatinine picrate increase as the temperature risess and decrease again as it falls (Owen et al., 1954) The increase in this laboratory is as much as $14 \%$ for alkaline picrate and $12 \%$ for alkaline creatinine picrate, between $15^{\circ}$ and $25^{\circ} \mathrm{C}$. It is therefor $\overrightarrow{\mathrm{e}}$ essential that the colours should be read with the blank, standards, and unknowns all at the same temperature. Here the readings were made at. room temperature, since if, as has been recomo mended, the samples are brought to $25^{\circ} \mathrm{C}$., the ${ }^{\circ}$ may cool unequally in cold weather, before all the readings are made.

Creatinine and Extraneous Chromogen Serum.-Table I shows the true creatinine concen

TABLE 1

CREATININE AND EXTRANEOUS CHROMOGEN IN SERUM AND THE CREATININE EXCRETION AND CLEARANCE

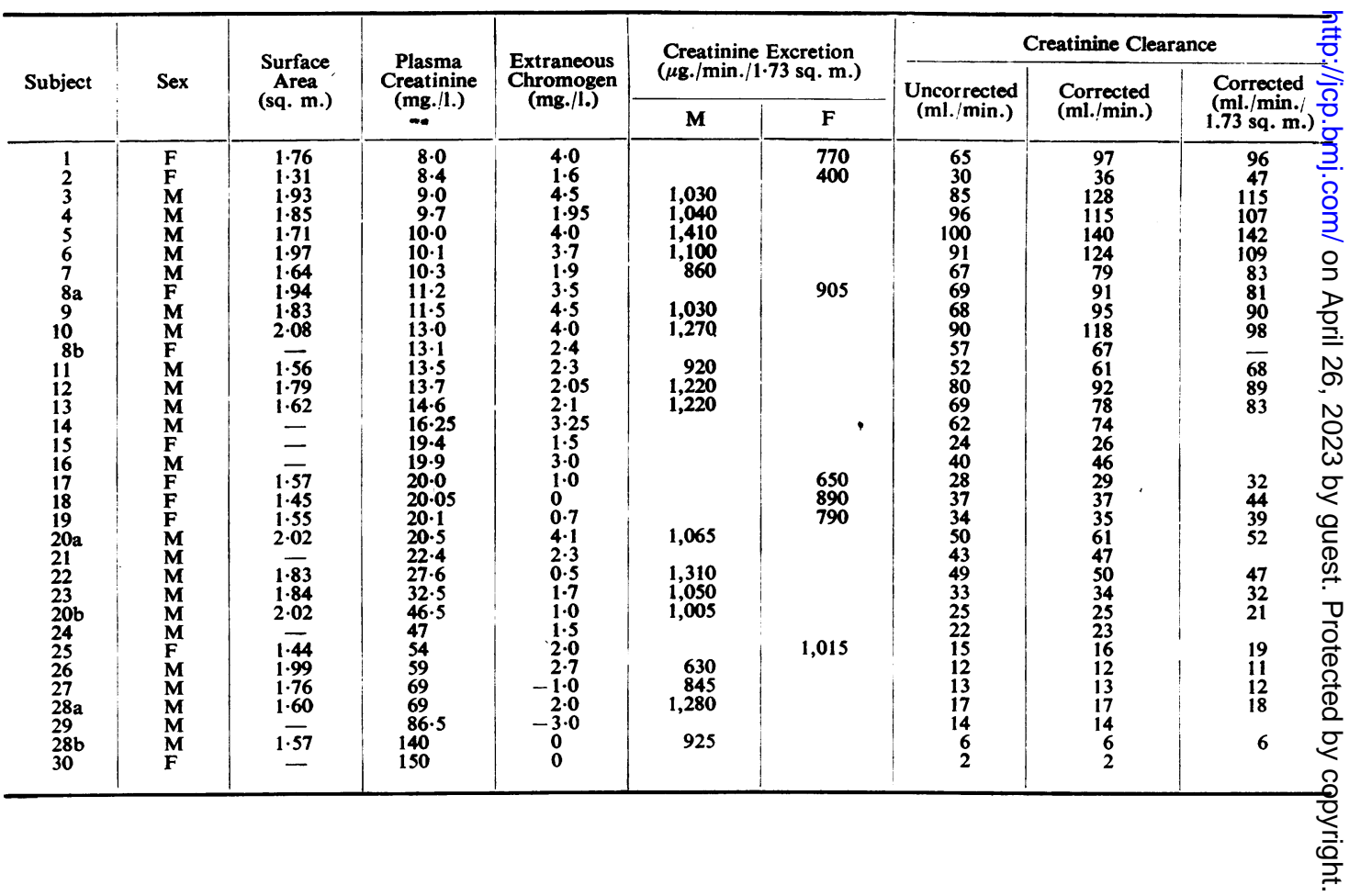


trations in 33 sera from 30 subjects and the extraneous chromogen concentrations. The extraneous chromogen varies from 0 to $4.5 \mathrm{mg}$./ litre. It does not increase as the true creatinine concentration rises, but rather tends to be less. The mean concentration in 14 subjects with serum creatinines below $15.0 \mathrm{mg}$. $/ \mathrm{l}$. (mean $11.15 \mathrm{mg}$./1.) is $3.0 \mathrm{mg} . / 1$, while in 10 subjects with serum creatinines of 15 to $33 \mathrm{mg}$./1. (mean $21.9 \mathrm{mg}$./1.) it is $1.8 \mathrm{mg}$./litre. These estimations were all carried out with 1 in 4 serum dilutions and may be compared ; but with still higher serum creatinines, when higher dilutions are used, a constant amount of extraneous chromogen gives a decreased colour response, soon falling within the error of estimation, so that it is not possible to say whether it remains constant or decreases.

The proportion of the total chromogen provided by extraneous chromogen thus decreases as the creatinine rises. It is in this series, $21.4 \%$ in 14 samples with a mean creatinine concentration of $11.15 \mathrm{mg} . / 1 ., 7.6 \%$ in 10 samples with a mean creatinine concentration of $21.9 \mathrm{mg}$. $/ 1$., and $2.2 \%$ in five samples with a mean creatinine concentration of $55.1 \mathrm{mg}$. / litre.

Creatinine Clearance.-Since the creatinine clearance is given by the minute excretion of creatinine divided by the plasma creatinine, if the total chromogen is used in its calculation it will be too low. The depression will be greater the higher the proportion of extraneous chromogen, and, since this is most in normal subjects with low

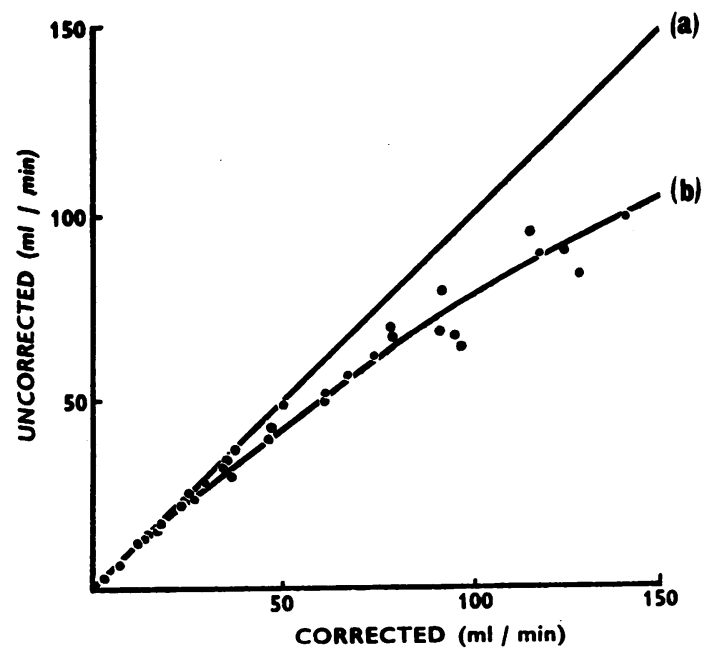

FIG. 1.-A comparison of the corrected and uncorrected values for creatinine clearance. The lines are those on which the points will lie $(a)$ if there is no extraneous chromogen in plasma, (b) if the extraneous chromogen is always $3 \mathrm{mg} . / \mathrm{l}$. and the creatinine excretion rate $1,100 \mu \mathrm{g} \cdot /$ minute. plasma creatinines, it follows that the error will be greater in these, and will decrease as the plasma creatinine rises. The uncorrected and corrected clearances are shown in Table $I$ and the difference is seen to be as much as $43 \mathrm{ml}$./ $\mathrm{min}$. in one case with a corrected clearance of $128 \mathrm{ml}$./min., while it is never more than $6 \mathrm{ml} . / \mathrm{min}$. when the corrected clearance is less than $50 \mathrm{ml} . / \mathrm{min}$. The corrected and uncorrected clearances are also compared in Fig. 1, where the decreasing difference at lower values is clearly seen. The curve shows the depression which will be produced if the creatinine excretion is $1,100 \mu \mathrm{g} . / \mathrm{min}$. and the extraneous chromogen $3.0 \mathrm{ml}$. / litre.

The clearances also depend on the minute excretion of creatinine. This is given in Table I for those cases where the surface area is known. The excretion rate, corrected for surface area, is higher in men than in women, the means being $1,076 \mu \mathrm{g} . / \mathrm{min}$. in $17 \mathrm{men}$ and $774 \mu \mathrm{g}$. $/ \mathrm{min}$. in seven women. There are also large variations in rate within the male and female groups. There is no obvious falling off in excretion at lower filtration rates.

\section{Discussion}

Miller and Dubos (1937) estimated extraneous chromogen in serum, after destruction of the creatinine with an enzyme, and found it to be responsible for $10 \%$ of the total colour in normals, but for up to $50 \%$ in cases of nephritis with raised creatinine levels. In a later paper, however, Miller and Miller (1951), using both the enzymatic and the adsorption method, showed that, while $20 \%$ of the total chromogen was extraneous in normals, this decreased to $10 \%$ when the plasma creatinine was 10 times normal and to $5 \%$ when it was 20 times normal. Brod and Kotátko (1949) used adsorption with Lloyd's reagent and found 1.2-4.0 mg./1. (mean $2.8 \mathrm{mg}$./1.) of extraneous chromogen in sera from normals, but in renal failure this increased up to $135 \mathrm{mg}$./1. or $24 \%$ of the total chromogen. Hare and Hare (1949), with adsorption, again found approximately $20 \%$ of the total chromogen in normals to be extraneous, but only $10 \%$ or less in chronic renal insufficiency. Ralston (1955), with adsorption, found $2.8-5.0 \mathrm{mg}$./1. of extraneous chromogen in sera from 10 normals, or a mean of $36 \%$ of the total chromogen.

These results all agree in that in normals approximately $20 \%$ of the total chromogen is found to be extraneous and this has also been shown in the present work. When the true creatinine is increased the results of different workers vary widely, but the suggestion that the 
extraneous chromogen accumulates and increases in the blood as kidney function fails is not on the whole supported, and this certainly does not occur in the cases studied in this paper where there is no increase or a fall.

Since the extraneous chromogen does not increase as the plasma creatinine rises and creatinine clearance falls, the error introduced by use of the total chromogen instead of the creatinine decreases, and when the plasma creatinine is more than twice normal, or the creatinine clearance less than $50 \mathrm{ml} . / \mathrm{min}$., it is usually negligible. On the other hand, with normal plasma creatinines the error may be very considerable, and, since the extraneous chromogen is by no means constant, it is not possible to correct by subtracting a mean value from the total chromogen, when this is the only estimate that has been made.

The clearance also depends directly on the creatinine excretion, and this varies widely. The lower excretion in females than males is related to the naturally lower clearances, but the variation found in one sex is sufficient to give a $50 \%$ difference in clearance, with the same plasma creatinine. This finding is not in agreement with that of Steinitz and Türkand (1940) and Effersøe (1957); the latter considered that the excretion is so constant for males or females respectively that the clearance can be calculated from the plasma value to within $20 \%$. He used 24-hour clearances and ensured that the plasma creatinine was not changing, whereas here some clearances are only based on a few hourly samples and may not be representative. But in fact, in Case 2, with such a low excretion that, in spite of a low normal plasma concentration, the clearance is only $47 \mathrm{ml} . / \mathrm{min}$./ 1.73 sq.m., the excretion is the mean over 15 days during which the plasma creatinine did not alter.

A falling off in excretion rate in severe degrees of renal failure has been recorded by Steinitz and Türkand (1940). Here any such fall was obscured by an insufficiency of cases and the large variations even in normal subjects.

\section{Summary}

The total chromogenic material in serum filtrates, estimated by the Jaffé reaction, is compared with the true creatinine, separated from serum filtrates with Fuller's earth. Some practical points in the estimations are discussed.

The non-creatinine chromogen varies from 0 to $4.5 \mathrm{mg}$./ 1 . creatinine equivalents in 33 sera. The amount does not increase and may even fall as the creatinine concentration rises.

If the total chromogen in plasma is used to calculate the endogenous creatinine clearance, this may be falsely depressed, the error being considerable in normal subjects, but decreasing as the filtration rate falls.

\section{REFERENCES}

Borsook, H. (1935). J. biol. Chem., 110, 481.

Brod, J., and Kotátko, J. (1949). Čas. Lék. čes., 88, 665.

Effersge, P. (1957). Acta med. scand., 156, 429.

Gaebler, O. H., and Keltch, A. K. (1928). J. biol. Chem., 76, 337.

Hare, R. S., and Hare, K. (1949). Fed. Proc., 8, 68.

Miller, B. F., and Dubos, R. (1937). J. biol. Chem., 121, 457.

Miller, Z., and Miller, B. F. (1951). Proc. Soc. exp. Biol. (N.Y.), 78 471.

Owen, J. A., Iggc, B., Scandrett, F. J., and Stewart, C. P. (1954). Biochem. J., 58, 426.

Ralson, M. (1955). J. clin. Path., 8, 160.

Roscoe, M. H. (1953). Ibid., 6, 201.

Steinitz, K., and Türkand, H. (1940). J. clin. Invest., 19, 285. 